\title{
2018 Yılında Ortada Kâr mı Var, Yoksa Zarar mı?: Türk Hava Yolları Vak’as1
}

\author{
What is The Annual Result of 2018: Income or Loss? \\ The Case of Turkish Airlines
}

\author{
Burcu Adiloğlu ${ }^{1}$, Göksel Yücel ${ }^{2}$ (1) \\ ${ }^{1}$ Doç. Dr., ${ }^{2}$ Prof. Dr., İstanbul Üniversitesi İşletme Fakültesi, Muhasebe Anabilim Dalı, İstanbul, Türkiye \\ ORCID: B.A 0000-0001-9680-1408; G.Y. 0000-0003-1940-8789
}

öz

Kamuyu Aydınlatma Platformu (KAP), 2019 yılının Mart ayında Türk Hava Yolları Anonim Ortaklığının Kurumlar Vergisi Geçici Beyannamesini Web sayfasında yayınlamıştır. Maliye’ye yönelik bu bildirimde 8 milyar Türk Lirasına yakın bir zarar yer almaktadır. Kısa sürede bu sonuç şirket hakkında olumsuz yorumlarla sosyal medyada paylaşılmaya başlanmıştır. Şirketin UFRS esaslı finansal tabloları ise bir süre sonra şirket Web sayfasında ve KAP'ta paylaşılmıştır. Burada ise şirket UFRS'ye göre 4 milyar Türk Lirası kâr bildirmektedir. Bu farklı sonuçların neden olduğu kargaşa sosyal medyada ve hatta diğer medya ortamlarında ele alınmaya başlamıştır. Vak’ada bu durum üç eski arkadaşın yer aldığı bir senaryoda, Türk Hava Yollarının kullandığı fonksiyonel para konusu da ele alınarak tartışılmaktadır. Senaryo rahat okunması için biraz değiştirilmiş olmakla birlikte, özünde yaşanmıştır.

Anahtar kelimeler: Türk Hava Yolları, Mali kâr (zarar), UFRS kârı (zararı), Fonksiyonel para

\section{ABSTRACT}

At the beginning of March 2019, the Public Dislosure Platform (of Turkey-PDP) disclosed the Provisional Corporate Tax Return of Turkish Airlines for the year 2018, on its Website. In this tax purposed statement, there was a loss of about 8 billion Turkish Liras. This result was widely discussed on social media, as was the the poor performance of the company's management. Shortly after that the company disclosed its IFRS based statements, and do PDP. According to IFRS Turkish Airlines had an income about 4 billion Turkish Liras. This discrepancy was also discussed not only on social platforms, but also on television programs. In this case, these results are discussed between old classmates including the functional currency concept. With the aim to make the text more reader friendly, some changes have been made in the case scenario, but most of the discussions were actual discussions which took place.

Keywords: Turkish Airlines, Taxable income (loss), IFRS income (loss), Functional currency

\section{Şirket Hakkında}

Türk Hava Yolları Anonim Ortaklığı 1933 yılında Havayolları Devlet İşletme İdaresi adıyla Milli Savunma Bakanlığına bağlı olarak kurulmuş, iki yıl sonra Bayındırlık Bakanlığına bağlanmıştır. 1938 yılında bu kez Ulaştırma Bakanlığına aktarılmış ve adı Devlet Hava Yolları Umum Müdürlüğü olmuştur. 1955 yılında ise anonim şirket haline dönüştürülmesine yönelik yasal düzenleme yapılmış ve 1 Mart 1956 yılında faaliyete geçmiştir. Kuruluşunda büyük ortak Hazine Müsteşarlığ iken Anonim Ortaklık statüsü gereği az sayıda özel sektör katılımı da vardı.

Başvuru/Submitted: 09.07.2019 Kabul/Accepted: 22.07.2019

Sorumlu yazar/Corresponding author: Burcu Adiloğlu / adiloglu@istanbul.edu.tr

Atıf/Citation: Adiloglu, B. ve Yucel, G. (2019). 2018 yılında ortada kâr mı var, yoksa zarar mı?: Türk Hava Yolları vak'ası. Muhasebe Enstitüsü Dergisi - Journal of Accounting Institute, 61, 103-112. https://doi.org/10.26650/MED.2019589139 
2005 yılında sermaye yapısı yeniden değişmiş, hisselerin \% 50,88'i Borsa İstanbul'da (başlangıçta İMKB) halka arz edilir duruma gelmiştir. Halen geri kalan \%49,12'lik kısım Türkiye Varlık Fonu'na aittir. Şirketin kayıtlı sermaye tavanı 5 milyar TL olup, şirket bu tavanı kullanmamış olup, 31.12.2018 tarihi itibariyle 1.380.000.000 TL ödenmiş sermayeye sahiptir. 2018 sonu itibariyle 15 adet bağl1 veya müşterek yönetime tabii ortaklığa sahiptir.

1933 yılında 5 mütevazı uçakla çıktığı yolculuk 31.1.2018 itibariyle 332 uçakla devam etmektedir. Uçakların ağırlığını oluşturduğu sabit kıymetlerin büyüklüğü nedeniyle, ülkenin en yüksek aktif toplamına sahip şirketidir. İlk yurtdışı seferini 1947 yılında Atina'ya yapan THY, bugün 124 ülkede 311 şehre uçarak Dünya'da en fazla noktaya uçuş yapan havayolu özelliği taşımaktadır. Uçak sayısı ve sunduğu koltuk sayısı itibariyle Dünya'nın ilk on havayolu şirketi arasındadır. 2018 yılında taşıdığı yolcu sayısı bir önceki yıla göre yüzde 9,5 artışla 75 milyon kişiye ulaşmıştır.

Ülkenin bayrak taşıyııı havayolu olan THY, Avrupa basketbolunun en önemli yarışması olan Euroleague'e ismini vermesinin yanı sıra, diğer sportif ve sosyal girişimleriyle marka çalışmalarını da üst düzeye taşımaktadır.

Ülkenin en önde gelen şirketlerinden olması nedeniyle faaliyet sonuçları kamuoyunda ilgi ile izlenmektedir.

\section{Üç Arkadaşın Sohbeti:}

Nizami Ondalıkoğlu, Şahin Yılmazbayhan ve Osman Dehrioğlu çocukluklarından beri birbirlerinden kopmamış üç yatılı okul arkadaşı idiler. Nizami Bey yıllarca Amerika Birleşik Devletleri’nde büyük bir havayolu şirketinde görev yapmış, on y1l kadar önce Güney Amerika’da bir ülkede şirketin ülke müdürlüğüne tayin edilmiş, kısa bir süre önce de emekliye ayrılmış, Bodrum'a yerleşmişti. Şahin Yılmazbayhan ise Avrupa ve Türkiye'de uluslararası bir muhasebe firmasının üst düzeyinde görev yapmış, ancak daha çalışabilecek enerjisi olmasına rağmen görevinden ayrılmış ve o da Bodrum’a taşınmıştı. Üçüncü kişi olan Osman Dehrioğlu ise uzun yıllar büyük kulüplerde voleybol oynamış, sonra ticaretle uğraşmış, sonunda o da organik tarım ile uğraşmak için aynı ilçeye göç etmişti. Sporculuk yıllarında öğrenciliğini biraz uzatmış olmakla beraber iktisat eğitimini tamamlamış olan Osman Bey, iktisadi ve mali konulardan sohbet etmeyi çok severdi.. Sosyal medya ortamında da çokça haberleşen üç arkadaş 2019 yılının Mart ayında bir akşamüstü sohbeti için yine bir araya gelmişlerdi.

Biraz havadan sudan söz ettikten sonra Nizami Bey, arkadaşı Osman’a sordu: “Geçen gün Türk Hava Yolları'nin 2018 yılında 7 milyar Türk Lirasının üstünde, hatta 8 milyar zarar ettiğini yazmışsın. Hatta şirketi de acımasızca eleştirmişsin. Nereden buldun bu bilgiyi? Ylllarca havayolları yöneticiliği yaptığım için, konu ilgimi çekti. Çünkü THY son yıllarda yaptı̆̆ı atılımlarla önemli bir Dünya şirketi olma yolunda..."

"Nereden olacak, Kamuyu Aydınlatma Platformundan... Telefonumda hala kayıtll.." dedi Osman Bey ve bulduğu resmi arkadaşına tekrar gösterdi. (Ek 1) 


\section{Ek 1}

\section{e kap.org.tr}

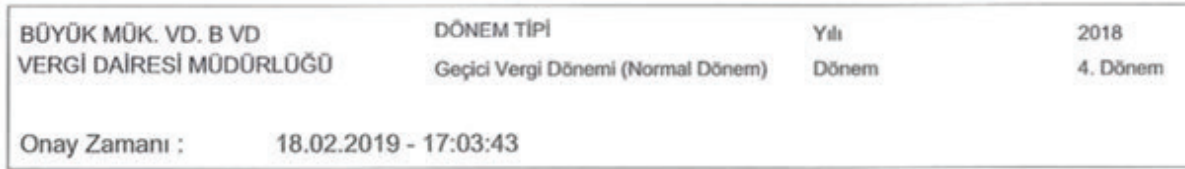

\begin{tabular}{|llll}
\hline Vergi Kimlik Numarası & 8760047464 & & \\
E-Posta Adresi & ZEKERIYADEMIR@THY.COM & & \\
Ticaret Sicil No & 75184 & Irtibat Tel No 212 & 4636480 \\
Soyadı (Unvanı) & TORK HAVA YOLLARI A.O. & & \\
Adı (Unvanın Devamı) & & & \\
\hline
\end{tabular}

Ticari Bilanço Kan

Kanunen Kabul Edilmeyen Gider

ZARAR OLSA DAHI INDIRILECEK ISTISNA VE INDIRIMLER

Tữù

Iştirak Kazançlan (K.V.K Mad. 5/1-a)/(Diger)

Diger Indirimler ve Istisnalar

Zarar Olsa Dahi Indirilecek Istisna ve Indirimler

Kar ve llaveler Toplamı

Zarar ve Indirimler Toplamı

Zarar

Kar

Mahsup Edilecek Geçmiş Yıl Zararları

Indirime Esas Tutar

Toplam

Dōnem Zaran

Işletmeden Çekilen Enflasyon Düzeltmesi Farkları

Safi Geçici Vergi Matrahı

KVK'nın 32/A Mad. Kapsamında Indirimli Kurumlar Vergisine (Geçici Vergiye) Tabi Matrah

KVK'nın 32/A Mad. Kapsamında Indirimli Kurumlar Vergisi (Geçici Vergi) Oranı

ZARAR

$204.654 .443,00$

8.319.872.798,00

$7.828 .703 .466,00$

$10.196 .238 .390,00$

\begin{tabular}{lr} 
Açıklama & \multicolumn{1}{c}{ Tutarı } \\
THY OPET AS VE TGS AS & $150.087 .475,00$ \\
\hline 018 YILI ICCIN PERSONELE & $54.566 .968,00$
\end{tabular}

KAR

$491.169 .332,00$

0,00

0,00

0,00

7.828.703.466,00

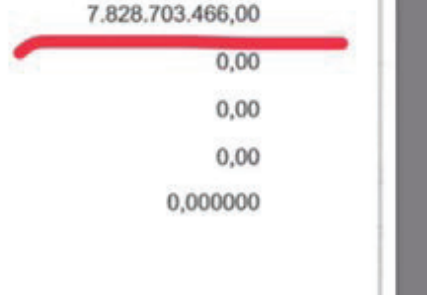

"Başarllyyı diyorlar, ama sonuç ortada.." diye tamamladı Osman Bey. Nizami Bey ise "Hayret ettim... Çok garip geldi bana." diyerek cevapladı. O ana kadar, konuşmaya katılmak konusunda isteksiz olan Şahin Bey, dayanamayıp "Yahu Osman, karışma şu işlere. Sen organik tarımınla uğraş. Yalan yanlış bilgiler paylaşma. Senin zarar dediğin, eskiden çok 
kullandı̆̆ımız tabirle mali zarar, yani Maliye’ye bildirilen rakam. Bunun şirketin performansı ile ilgisi yok. Nereden bulursun bunları..." Osman Bey kızmıştı: "Şahin, senin gibi yıllarca bu işlerle uğraşmadım. Ama ben de ticari kâr nedir, mali kâr nedir, bilirim. Hem üniversitede bu konuları okudum, hem de ylllarca ticaret ile uğraşırken vergi beyannamesi verdim. Bak, senin dediğini esas alırsak ticari zarar daha da fazla, 8 milyarın üstünde...” Resimde altı çizili, üstteki rakamı gösterdi: Ticari Bilanço Zararı: 8.115.218.355,00 TL.

"O da değil, şirketin performansı.. O başka bir rakam, ama şirketin sonucu o rakam da değil..." dedi Şahin Bey. Osman Bey, arkadaşına "Yillarca bu işlerle uğraştın, sadece ukalalık öğrenmişsin.. O değill, bu değil, sana da rakam beğendiremiyoruz.." Üçü de ilerlemiş yaşlarına rağmen çocukluktan bu yana beraber büyümüş olmanın rahatllğı ile konuşuyorlardı.

Nizami Bey de şaşırmıştı, "Peki gerçek nedir Şahin?" diye sordu. Şahin Bey, biraz da bıkkınlıkla, "Yahu ben işlerden bıktım, buralara kaçtım. Yine bana kurcalatıyorsunuz bu konulart... Siz hiç UFRS diye bir şey duydunuz mu? Onu duymanız da yetmez... Fonksiyonel para diye bir şey duydunuz mu? Türk Hava Yollarının para biriminin ABD doları olduğunu biliyor musunuz?" Nizami Bey, "Biz bizim şirkette uygulamiyorduk. Ama biraz duymuştum IFRS'i (UFRS). Biz Amerikan standartlarl kullanırdı, US GAAP diye bilinen." Osman Bey de, "Ne demek fonksiyonel para? Bir de bu klsaltmalar neyin nesi? Ayrıca tabii ki, THY Dünya kendini tanıtmak için tablolarını dolara da çevirebilir... Üff, şimdi kötü olacak. 7 milyar liranın üstündeki zarar kaç dolar yapar?” Şahin Bey, “ìi, bir de dolara çevirip paylaş o zararı sosyal medyada.. Bir o eksikti. Yahu, başkası anlasın diye hazırlanan, örneğin dolara çevrilen tablolardan bahsetmiyorum. O İngilizce'si ile 'reporting currency'. Benim dediğim başka."

"O zaman şu işin aslını anlatsana bize Şahin.." dedi Nizami Bey. Şahin Bey, "Başka zaman. Mesela yarın buluşalım, benim işim yok. Şimdi bunun arazisine gidip (Osman Bey'i işaret etti), bana gezen tavuk çiftliği yapabilecek kü̧̧ük bir alan var mi, ona bakacağız. Hem ben de bu arada Internet'ten size bazı şeyler indirir, yanıma alırım. Yarın konuşuruz. Sizlerin kafası karışmışsa, başkalarının hali ne olur, bilemiyorum” dedi. Ertesi gün buluşmak üzere ayrıldılar.

\section{Ertesi Gün}

Akşamüstü aynı çay bahçesinde buluştuklarında, Şahin Bey hazırlıklı gelmişti. Elinde bir takım bilgisayar çıktıları vardı. "Osman Bey, lütfen yakınıma oturunuz.." diye takıldı arkadaşına. Şahin Bey, meslek hayatı sırasında yarı zamanlı olarak da bazı üniversitelerde ders vermişti. Oradan kalan alışkanlıkları ile ders verir gibi anlatmaya başladı. Nizami Bey de dikkat kesilmişti.

"Öncelikle bir şirketin amacının ne olduğunu konuşmakla başlayalım. Çoğu kişi 'kâr etmek' diye cevaplar. İlk baklşta doğru gibi gelir, ama daha sonra uzun süreli kârlllık, şirket piyasa değerinin en yükseğe çıkartılmast, sürdürülebilirlik gibi kavramlara geçilebilir. Doğrudur da.. Ama kamuoyu için bence en önemli kavram kârdır. Herkes geçmişte de o rakamı konuşurdu, gelecekte de onu konuşacaktır. Bir şirketin, hele kamuya mal olmuş bir şirketin, toplumda biraktığı en önemli etki 'kâr' rakamıdır. Bunu biraz da toplumbilimciler incelemelidirler. Ama bakın biz bile burada 'kâr' rakamını konuşuyoruz. Şimdi gelelim en önemli meseleye... Kâr, öyle hassa terazide ölçülmüş bir rakam filan değildir. Aslında belki de kârın en doğru ölçümü bir şirketin piyasa değerinde yılbaşından yllsonuna meydana gelen artı̧̧ biçiminde olabilir. Ancak bu kez de piyasa değerinin ölçülmesi başka sorunlar getirir. Bu nedenle biz de muhasebenin hesapladı̆̆ı kâr rakamını kullanırız. "

"Amma uzattın yahu, ben hangi rakamla konuştum sanki?" diye araya girdi Osman Bey. Şahin Bey, "Sen sussana biraz, okulda da böyleydin zaten, dinlemeye devam et." dedi ve konuşmasını sürdürdü. "Kâr ile ilgilenen otoritelerin başında bir ülkenin maliyesi gelir. Vergi amaçları için. Şimdi senin bulduğun rakamları alt alta yazalım.

Dönem zararl: 7.828.703.466,00 TL

Ticari Bilanço Zararı: 8.115.218.355,00 TL

Bunun ikisi de THY performansını göstermez. Öncelikle Ticari bilanço zararı denilen rakam Vergi Usul Kanunu hükümlerine 
göre tutulan defterlerde hesaplanmış rakamdır. Ancak bunun içinde VUK çerçevesinde bir gider olarak indirime konu teşkil etmeyen, oradaki ifade ile 491 milyon TL 'Kanunen Kabul Edilmeyen Gider' var. Yani bunlar şirket gideridir ama, vergi mevzuatı vergilendirmede indirilebilecek bir gider olarak görmez bunları. THY'de bunlar nedir, bu kadarlk bilgi ile çözemem. Ama söz gelimi vergi cezaları buna örnek olabilir. Ya da trafik cezası.."

"Hatalı sollama nedeniyle uçaklara kesilen cezalar mı yani?" diye şakalaştı Osman Bey.

"Sus ve dinlemeye devam et. Ne bileyim ayrıntısını... Bu 491 milyon TL ticari bilanço zararından düşülmüş. Kâr çıssaydı eklenecekti, pek tabii.. Ayrıca mükerrer vergilemeyi önlemek için THY'nin iştiraklerinden sağlanan kazançlar da kârda düşülecektir. Burada zarar olduğu için eklenmiş. Sonuç vergilendirilecek rakam, ki zarar olduğu için vergilendirme olmayacağ tabiidir, 7,8 milyar TL. Anlatabildim mi?" Şahin Bey’in bu açılamalarına Nizami Bey de müdahale etti. “Osman da farkll şeyler söylemedi ki ama..” diyerek arkadaşını savundu.

"Durun, daha yeni başladım." diyerek devam etti Şahin Bey. "Bir ülkenin vergi mevzuatı, değişik nedenlerle, şirket gerçeklerini farklı biçimde ölçebilir. Bunların başında gelen bir tanesi, yatırım teşviki olması için sabit klymetler ilk yıl hangi gün alınırsa alınsın, şirkete tam ylllık amortisman gideri hesaplama imkanı verilmesidir. 1949 yllından beri böyledir. 1994'te kaldırllmış, ama tepkiler üzerine hemen geri gelmişti bu hüküm." "Yok canım dedi" Osman Bey, "ben ticaret yaparken bu avantajdan yararlanmak istedim, binek otomobil aldım Arallk aylnda, saymadllar..." "Sen de gidip istisna olanı bulmuşsun, uyanık Osman" diye güldü Şahin Bey.

"Şimdi, Türk Hava Yollarının hemen her yıl çok sayıda uçak aldı̆̆ını dikkate alırsanız, amortisman giderinin büyüklüğünü hayal edebilirsiniz. Bitmedi, Maliyemiz sabit klymetler için amortisman ömürleri belirlemiştir. Çoğunlukla gerçekçi sürelerdir. Ama uçaklar için belirlenen ekonomik ömür sadece 6 yıldır, sonra 2010'ların başında 10 yıla çıkarıldı." Bu noktada Nizami Bey hemen devreye girdi. "Olur mu, bir uçağın ekonomik ömrü su içinde 20-30 yıldır. Bu işi de ben bilirim.." Şahin Bey devam etti, “Tamam işte bu hava taşımacllı̆̆ sektörüne bir özel teşviktir. Bu gibi teşvikler birçok ülkede vardır. Ama bitmedi, bir de tam tersi var. Vergi mevzuatı bazı şirket giderlerini de caydırma amaçlı olarak gider kabul etmeyebilir. Söz gelimi, vergi cezaları. Yine bitmedi, teşvik veya caydırma amaçlı farklllıkların yanı sıra mevzuatın güncellikten uzak kalmış olması nedeniyle de farklllı olabilir. Söz gelimi geçmişte Türkiye'de yıllarca büyük ölçekli enflasyon yaşanmasına rağmen, vergi mevzuatında uzun yıllar kapsamlı bir düzenleme yapılmamıştı. Ya da kıdem tazminatlarının ancak fiilen ödenmesi öncesinde ylllık gider olarak kabul edilmemesi daha güncel bir örnek olabilir. Özetle, teşvik, caydırma ve güncellikten uzak kalmış hükümler nedeniyle vergi mevzuatı tabloları sadece vergilendirme amacıyla kullanılabilir. Şirket performansı ölçmekte değil..."

Bu noktada Osman Bey biraz da suçlu biçimde "İyi de, ben bu bilgiyi Kamuyu Aydınlatma Platformunda bulan birinden paylaşmıştım." dedi.

“Kamuyu Aydınlatma Platformu şirketin Maliye’ye verdiği bilgiyi yayınlayarak bence kafa karışıklı̆̆ yaratmış. Asıl paylaşılması gereken şirketin gelir ve giderlerini gerçekçi biçimde ölçmeye çalışan standartlara göre hazırlanan tabloyu paylaşmasıydı. Bunu da yayınlar mutlaka, ama geç kalmıı̧... Her neyse, ben şirketin Web sayfasından bu bilgileri buldum. Uluslararası Finansal Raporlama Standartlarına göre hazırlanan tablo burada. Bizdeki adiyla Türkiye Muhasebe Standartları. Bunların amacı gelir ve giderlerini gerçekçi biçimde ölçmektir. Kamuya açıklanması esas açılanması gereken budur. Görüldü̈̆̈̈ gibi, dönem kârl, ki orada 'sürdürülen faaliyetler dönem kârı' olarak yer allyor. 4 milyar Türk Lirasının biraz üstünde. Sonuç: THY 2018 yllında en iyi ölçüm olduğunu kabul ettiğimiz UFRS'ye göre 4 milyar TL kâr etmiştir. (Ek 2) Ortada zarar filan yoktur. UFRS vergi mevzuatından farklı ölçer gelir ve giderleri. Sonuçlarl gerçekçi ölçebilmektir amaç, söz gelimi önemli farklllikların başında gelen amortisman konusunda kalkıp da yıl ortasında alınan uçağa tam yıllık amortisman gideri hesaplanmaz. Keza amortisman ömürlerini şirket yönetimi belirler. Sorarsinız diye baktım. UFRS'ye göre THY, uçak gövde ve motorlarına ekonomik ömür 25 yll biçiminde belirlenmiş. Sadece amortismanların etkisi nedeniyle ortada vergilendirilecek bir kârın kalmaması gayet doğaldır. Uçak fiyatlarının yüksekliğini en iyi Nizami bilir aramızda.." 
Ek 2

TÜRK HAVA YOLLARI ANONIM ORTAKLIĞI VE BAĞLI ORTAKLIKLARI

31 Aralık 2018 Tarihinde Sona Eren Hesap Dönemine Ait

Konsolide Kar veya Zarar ve Diğer Kapsamlı Gelir Tablosu

(Tutarlar, aksi belirtilmedikçe, Milyon Türk Lirası (TL) olarak gösterilmiștir.)

\author{
KAR VEYA ZARAR KISMI \\ Hasilat \\ Satışların Maliyeti (-) \\ BRÜT KAR \\ Genel Yönetim Giderleri (-) \\ Pazarlama ve Satıș Giderleri (-) \\ Esas Faaliyetlerden Diğer Gelirler \\ Esas Faaliyetlerden Diğer Giderler (-) \\ ESAS FAALIYET KARI \\ Yatırım Faaliyetlerinden Gelirler \\ Yatırım Faaliyetlerinden Giderler (-) \\ Özkaynak Yöntemiyle Değerlenen Yatırımların \\ Karlarından Paylar \\ FINANSMAN GELIRI ÖNCESI FAALIYET KARI \\ Finansman Gelirleri \\ Finansman Giderleri (-) \\ SÜRDÜRÜLEN FAALIYETLER VERGI ÖNCESI \\ KARI \\ Sürdürülen Faaliyetler Vergi Gideri \\ Dönem Vergi Gideri \\ Ertelenmiş Vergi Gideri \\ SÜRDÜRÜLEN FAALIYETLER DÖNEM KARI \\ DÖNEM KARININ DAĞILIMI
}

\section{DÍĞER KAPSAMLI GELIRLER}

Kar veya Zararda Yeniden Sınıflandırılacaklar

Yabancı Para Çevrim Farkları

Gerçeğe Uygun Değer Farkı Diğer Kapsamlı Gelire

Yansıtılan Finansal Varlıklardan (Kayıplar)/Kazançlar

Gerçeğe Uygun Değer Farkı Diğer Kapsamlı Gelire

Yansıtılan Finansal Varlıklara İlişkin Diğer Kapsamlı Gelir, Vergi Etkisi

Nakit Akış Riskinden Korunma Kazançları/(Kayıpları)

Özkaynak Y öntemiyle Değerlenen Yatırımların

Nakit Akış Riskinden Korunma Kazançları/(Kayıpları)

Nakit Akış Riskinden Korunmaya İlişkin Vergi (Gideri)/Geliri

Kar veya Zararda Yeniden Sinıflandırılmayacaklar

Tanımlanmıș Emeklilik Planlarındaki Aktüeryal

(Kayıplar)/Kazançlar

Diğer Kapsamlı Gelirlere İlişkin Vergi Geliri/(Gideri)

DIGGER KAPSAMLI GELIR

TOPLAM KAPSAMLI GELIR

Pay Başına Kar (Kr)

Sulandırılmıș Pay Başına Kar (Kr)

Bağımsız Denetimden Geçmiş

\begin{tabular}{r} 
Dip \\
Refer: \\
\hline 2 \\
2 \\
2 \\
2 \\
2 \\
2 \\
3 \\
3 \\
3 \\
3 \\
3 \\
3 \\
3
\end{tabular}

32

32

31

31

30

1 Ocak -

Denetimden Geçmiş

ransla

31 Aralık 2018

27

28

28

29

29

(1)

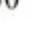

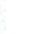

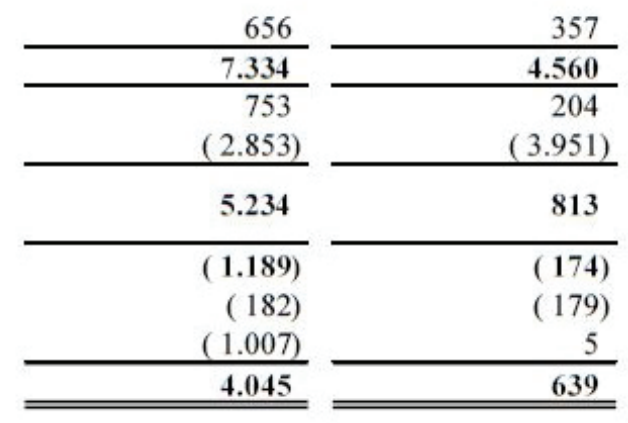

(49.284)

13.569

(1.238)

(6.185)

808

(762)

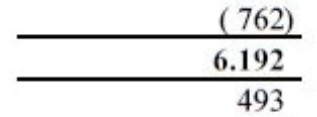

(7)

31 Aralık 2017
39.779

$\frac{(31.943)}{7.836}$

$\begin{array}{r}(126) \\ \hline 3.568 \\ \hline 640\end{array}$

640

5)

7.246

7.516

1.651

(50)

4

10

\begin{tabular}{|c|c|c|}
\hline & 8 & (41) \\
\hline & 88 & (47) \\
\hline & (129) & (18) \\
\hline & (161) & (23) \\
\hline & 32 & 5 \\
\hline & 7.117 & 1.633 \\
\hline & 11.162 & 2.272 \\
\hline 33 & 2,93 & 0,46 \\
\hline 33 & 2,93 & 0,46 \\
\hline
\end{tabular}


Nizami Bey, arkadaşı Şahin'e dönerek "Şimdi oldu, o zaman bizim Osman anlamadan paylaşıp, olumsuz izlenim yaratmış şirket hakkında. Ancak sen dün bize fonksiyonel para filan diye de birşeyler söyledin, o ne iştir?" Şahin Bey, bıkkın bir ifade ile “Kurtuluş yok, şimdi onu dinleyin. Ama Osman çay ısmarlasın birer tane daha..." dedi.

\section{Türk Hava Yollarının Para Birimi}

Çaylar geldiğinde Şahin Bey yeniden konuşmaya başladı. "Hepimiz okul yıllarında muhasebe dersleri aldiğımızda, hocalarımız bize muhasebede ölçü biriminin para olduğunu söyledi. Ama hiçbirimizin aklına 'hangi para' diye sormak gelmemişsir. Herkes bulunduğu ülkenin para birimini hayal etmişsir herhalde. Halbuki bulunduğunuz ülkenin para birimi sizin gerçeklerinizi yansıtmayabilir. Örnek vereyim, Dünya'nın ücra bir yerindeki bir ülkede görevlendirildiniz. Maaşınız dolarla ödeniyor, bir otelde kalı, yeme içme dahil ücreti dolar ile ödüyorsunuz. Arabanızı, benzininizi size oraya gönderen kuruluş sağllyor. Özetle ülkenin parast ile temasınız son derece sinırlı bazı küçük harcamalarda kalyyor. Ö̈lkenin parasının dolara karşı değer kaybettiğini düşünün, cebinizdeki dolarlar o ülkenin parasina göre değer kazaniyor başka bir ifade ile... Şimdi siz kâr mı ediyorsunuz, tabii ki hayır.. Çünkü sizin için asıl olan, yani fonksiyonel para 'dolar'.. Hatta cebinizde bir miktar o ülkenin parasından varsa, daha az dolar alabileceğiniz için zarara uğruyorsunuz. Bu konuda doksanl yıllarda ülkemizde karşılaşılan bir durumdan bahsedeyim. Bir yabancı yatırımcı dolar getirerek şirket kuruyor. Parayı dolar olarak bankaya yatıriyor. Bir iş yapamadan takvim yll bitiyor. Ortada bir faaliyet dahi yok. Ne kâr var, ne de zarar. Ama ülkemizin parası ile bakınca, kurlar yukarlya seyrettiği için bu kişinin şirketi kur farkı kârl elde etmiş gözüküyor ve bunun üstünden de Maliye vergi isteyince tasını tarağın toplayıp ülkesine geri dönüyor. Aynıyla vakidir.”

"Ben de biliyorum böyle bir vak'a” dedi Osman Bey.

"Tamam işte, esas olan bir şirketin para birimin o ülkenin değil, bulunduğu ekonomik çevrenin para birimi olmasıdır. Yoksa sonuçlarl yanlı̧̧ ölçersiniz. UFRS'nin bu konuda düzenlemesi de vardır. Ekonomik çevrenin para birimi, yani şirketin ağırlkklı olarak kullandı̆̆ı para biri esastır. Standartların Türkçe tercümesinde 'geçerli para birimi' terimi kullanılmıştır. Türk Hava Yolları da Türk Lirasının performansını doğru ölçmediği düşüncesiyle para birimini ABD doları olarak belirlemiş̧tir. Hem de 2011 yllında. Dün akşam onu da buldum. Alın okuyun. Mali tablo politikalarının başında yazılı hem de.. " diyerek, akşam bulduğu anlaşılan elindeki dokümanı arkadaşlarına uzattı (Ek 3) Şahin Bey ve ekledi. "Şaşırtıcı gelecek size ama Türk Lirası THY için yabancı paradır, aynı Avro veya Japon Yeni gibi..”

\section{Ek 3}

\section{Geçerli para birimi değişikliği}

Şirket son yıllarda yaptığı yatııımlarla filosundaki uçak sayııını ve uçuş noktalarını önemli bir biçimde artıırmıştır. Ayrıca filoya katılan geniş gövdeli uçakların sayısındaki arış̦la birlikte, yurt dışından yurt dışına transit yolcu gelirlerinin toplam gelirler içerisindeki payı da artmışıır. Şirket'in uçuş ağının görece sınırlı bir coğrafi alandan küresel alana dönüşmesi ve isstanbul'u önemli bir uluslararası uçuş merkezi yapmaya yönelik stratejisi kapsamında, rekabet/faaliyet içinde bulunduğu coğrafyaların genişlemesi sebebiyle, TL'nin rekabet/ faaliyet unsurları açısından, Şirket'in bulunduğu temel ekonomik çevreyi yansıtmaktaki etkisi azalmıştır. Şirket yönetimi, ABD Doları'nın mevcut Şirket faaliyetlerine olan etkisini değerlendirmiş ve geçerli para birimini TL'den ABD Doları́na değiştirmeye karar vermiştir

Geçerli para birimi değişikliğine ilişkin altyapı çalışmaları 2011 yılının son çeyreğinde gerçekleştirilmiştir. Yapılan çalışmaların sonuçları ve geçerli para birimi değişikliğinin uygulanması tekniği dikkate alındığında, Şirket'in ekonomik ortam ve faaliyetlerindeki değişimin bir anda değil, bir zaman zarfı içinde gerçekleșmiş olması ve 31 Aralık 2010 tarihi itibariyle Türk Lirası finansal tabloların ABD Doları tarihi maliyet esasına göre hazırlanmış finansal tablolara tutarsal olarak çok yakın olması da dikkate alınarak, Şirket yönetimi geçerli para birimi değişikliğinin 2011 yılı başından itibaren uygulanmasının daha uygun olacağını değerlendirmiş ve Şirket'in geçerli para birimini 1 Ocak 2011 tarihinden itibaren geçerli olmak üzere ABD Doları olarak belirlemiştir. TL ise Grup'un sunum para birimi olarak kalacaktır.

"Bir yaşıma daha girdim. Yani THY'nin para birimi dolar ise, defterlerini hangi para ile tutuyor" diye sordu Osman Bey. “Özel bir izni yoksa, ki sanmiyorum, Türkiye'de defterler Türk Lirast ile ve vergi mevzuatına uygun tutulmak zorundadir. Bunun sonunda senin bizi burada konuşturan meşhur tablon ortaya çıkar. Detaylarını bilemem, görüşmek gerekir. Ama bunlar önce UFRS'ye çevrilir, TL olarak, daha sonra fonksiyonel para olan dolara.. " Bu noktada artık tüm dikkatini vermiş olan Nizami Bey sordu: "Yani UFRS'ye uygun, ama vergi mevzatından farkll, ama TL ve gerçeği yine yansitmiyor. Doğru mu anladım?" "Evet" dedi Şahin Bey, "öyle olduğunu sanıyorum. Ama bu tablo gün ışığına çıkmaz, hemen fonksiyonel paraya dönüştürülür. Şimdi teknoloji yüksek olduğu için UFRS dönüştürmesini doğrudan dolarla da yapıyor ve 
böyle bir tablo elde etmiyor da olabilirler. Dediğim gibi, görüşmek lazım. Ama sonuçta ortaya UFRS'ye uygun fonksiyonel tablo çıkar. Para birimi dolardır."

Osman Bey bu konularda biraz bilgisiz olduğunu kabul ederek öğrenmek için sordu: "Peki UFRS ve TL olan tabloda zarar gözüktüğ̈̈ varsayalım, dolara çevirince kâra dönüşebilir mi, kur değişimlerine bağll olarak, ya da tersi olabilir mi?" "Tabii ki olabilir, örneğin TL tablo kâr gösteriyorken, fonksiyonel (dolar) zarar olabilir."

"Peki” dedi Nizami Bey, "senin bize getirdiğin UFRS diye belirttiğin tablo TL, bu ne oluyor?” "Şimdi,” dedi Şahin Bey, "bir sonraki aşamaya geçtik. Varsayınız ki dolar olarak hazırladığınız tabloları Japon Yeni’ne, ya da Hint Rupi’sine dönüş̧ürüp o ülkelere yolladınız, raporladınız yani. ISște bu durumda yen veya Rupi "raporlama para birimi'dir. Başkaları anlasın diye yaptınız. Tercümedir yani... “

Bu noktada Şahin Bey ilginin arttığını görünce "Durun dedi size bir şey soru sorayım. Varsayınız ki bir şirketin fonksiyonel parası dolar ve zarar gösteriyor. Ve siz bunu Japon Yeni’ne dönüştürdünüz, Japonlar rahat anlasın diye. Dolar-Yen kurlarına bağlı olarak zararın kâra dönüşme ihtimali olabilir mi? ” Osman bey hemen atladı ortaya “Olabilir..” Nizami Bey ise düşünüyordu. "Biz” dedi Şahin Bey, “çocukken Agatha Christie romanları okurduk, hatırlyorsunuz. Yazar onları tabii ki İngilizce yazardı. Varsayınız ki katil aşçıbaşı, Türkçe’ye çevirince katil bu kez yamağı çıkar mı”... Osman Bey yaptığı mantık hatasını farketti, güldü. “Çıkmaz tabii.. Yine zarar çıkar, ama Japon Yeni büyüklüğünde..”

Şahin Bey devam etti. "Şimdi sizin baktığınız tablo da, TL aynen Japon Yeni’nde olduğu gibi raporlama para birimi, sizler anlayasınız diye.. Bizim TMS buna sunum para birimi demiş."

Osman “özetliyorum” dedi.

“1.Vergi Beyannamesinde bir ticari kâr var, bu asıl performans sonucu değil.

2.Bunun bazı düzeltmelerle vergisel zarar haline dönüşmüşü var, bu hiç değil.

3.Bizim görmediğimiz bir UFRS TL tablo var (belki de yok), ama bu da henüz fonksiyonele dönüşmemiş olduğu için bu da performans sonucu değil.

4.Bunun fonksiyonele dönüşmüş, yani ABD doları olanı var. Ama o elimizde değil.

5.Biz anlayalım diye bunun raporlama amaçlısı yapılmış, TL olarak. Onu esas alacă̆ız. 4 milyar kâr”"

“Aferin Osman, öğreniyorsun bu işleri” dedi Şahin Bey, tebessüm ederek.

$\mathrm{Bu}$ arada elindeki telefonla oynayan Nizami Bey, “Durun dedi, THY'nin 2018 yll dolar tablosunu buldum. (Ek 4) 753 milyon dolar kâr gösteriyor. “ "Tamamdır işte. O da raporlama amaçlı. Ama şirketin fonksiyonel para biri de dolar olduğu için ikisi aynı." 
Ek 4

TÜRK HAVA YOLLARI ANONIM ORTAKLIĞI AND ITS SUBSIDIARIES

Consolidated Statement of Profit or Loss and Other Comprehensive Income

For the Year Ended 31 December 2018

(All amounts are expressed in Million US Dollars (USD) unless otherwise stated.)

\section{PROFIT OR LOSS}

Revenue

Cost of Sales (-)

\section{GROSS PROFIT}

General Administrative Expenses (-)

Marketing and Sales Expenses (-)

Other Operating Income

Other Operating Expenses (-)

OPERATING PROFIT BEFORE

INVESTMENT ACTIVITIES

Income from Investment Activities

Expenses from Investment Activities

Share of Investments' Profit Accounted

by Using The Equity Method

OPERATING PROFIT

Financial Income

Financial Expenses (-)

\section{PROFIT BEFORE TAX}

Tax Expense

Current Tax Expense

Deferred Tax Expense

NET PROFIT FOR THE YEAR

\section{OTHER COMPREHENSIVE INCOME}

Items That May Be Reclassified Subsequently To

Profit or Loss

Currency Translation Adjustment

(Losses) / Gains on Remeasuring FVOCI

Fair Value (Losses) / Gains on Hedging Instruments

$$
\text { Entered into for Cash Flow Hedges }
$$

Fair Value Gains / (Losses) Hedging Instruments of

Investment Accounted by Using the Equity Method

Entered into for Cash Flow Hedges

Related Tax of Other Comprehensive Income

Items That Will Not Be Reclassified Subsequently To

Profit or Loss

Actuarial Gains on Retirement Pay Obligation

Related Tax of Other Comprehensive Income

OTHER COMPREHENSIVE (EXPENSE) / INCOME

FOR THE YEAR

\section{TOTAL COMPREHENSIVE INCOME FOR THE YEAR}

Basic Gain Per Share (Full US Cents)

Diluted Gain Per Share (Full US Cents)

\begin{tabular}{|c|c|c|}
\hline Notes & 31 December 2018 & 31 December 2017 \\
\hline 26 & 12,855 & 10,958 \\
\hline \multirow[t]{2}{*}{27} & $(10,136)$ & $(8,762)$ \\
\hline & 2,719 & 2,196 \\
\hline 28 & $(260)$ & $(275)$ \\
\hline 28 & $(1,290)$ & $(1,127)$ \\
\hline 29 & 165 & 264 \\
\hline \multirow[t]{2}{*}{29} & $(143)$ & (36) \\
\hline & 1,191 & 1,022 \\
\hline 30 & 101 & 178 \\
\hline 30 & $(2)$ & (1) \\
\hline \multirow[t]{2}{*}{3} & 123 & 102 \\
\hline & 1,413 & 1,301 \\
\hline 31 & 129 & 56 \\
\hline \multirow[t]{3}{*}{31} & (588) & $(1,078)$ \\
\hline & 954 & 279 \\
\hline & $\overline{(201)}$ & $(56)$ \\
\hline 32 & $(40)$ & (49) \\
\hline \multirow[t]{2}{*}{32} & $(161)$ & (7) \\
\hline & 753 & 223 \\
\hline
\end{tabular}

( 120)

40

(52)

(2)

(9)

(86)

65

24

( 20)

(25)

(4)

(5)

\section{5}

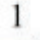

\begin{tabular}{|c|c|}
\hline$(140)$ & 36 \\
\hline 613 & 259 \\
\hline 0.55 & 0.16 \\
\hline 0.55 & 0.16 \\
\hline
\end{tabular}


Kendini konuya iyice kaptıran Nizami Bey “bir şey soracă̆ım. Bu tablonun altında 'Toplam Kapsamlı Gelir' 11,1 milyar TL diye bir ifade var. Ingilizce'sinde “Total Comprehensive Income For The Year” yazlyor, ama dolar olarak çok farkll, sadece 613 milyon dolar.. Hem sonra income kelimesini biz Amerika'da şirketler için kâr anlamında kullanırız, burada niye 'gelir' demişler?” Şahin Bey, ver bakalım şunları dedi. O sırada sohbetin bombası geldi. Bir süredir telefonundan elindeki Internet’i didikleyen Osman bey “Vergi Usul kanuna göre uçakların amortisman ömrü uzatılmış. Hem de kısa süre önce. 9 Mart 2019..(Ek 5) Bu ne anlam taşıyor şimdi?"

\section{Ek 5}

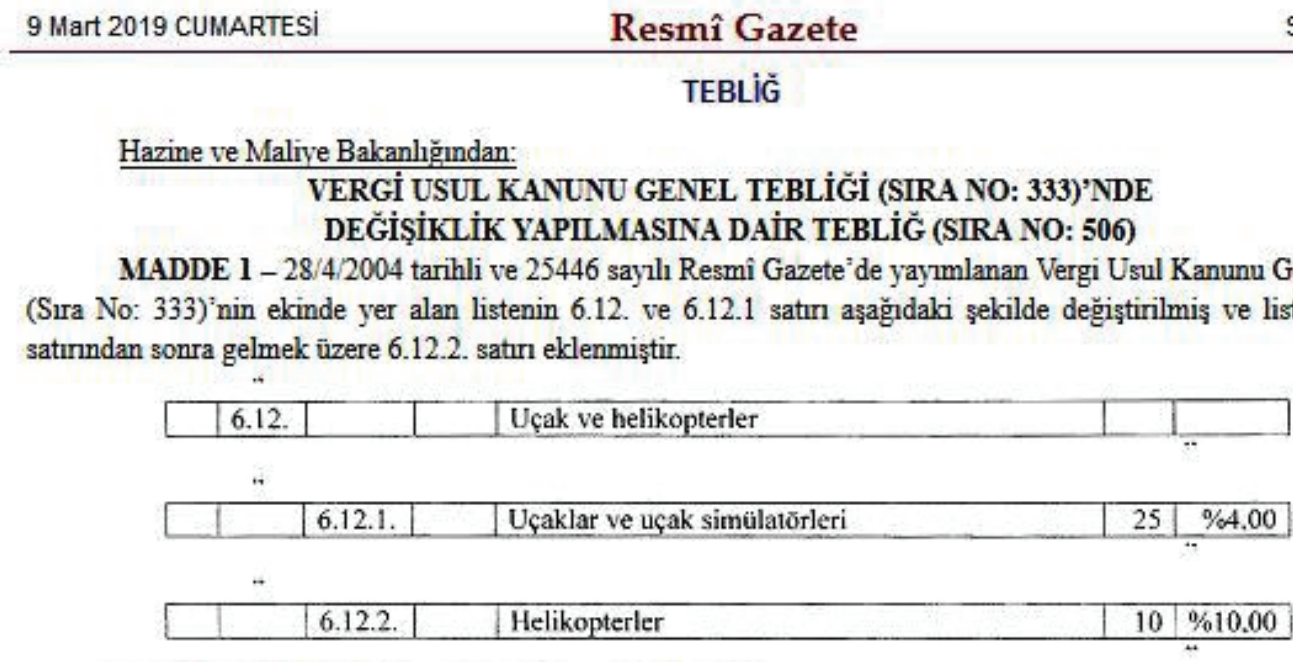

MADDE 2 - Bu Tebliğ yaymı tarihinde yürürlüğe girer.

MADDE 3 - Bu Tebliğ hükūmlerini Hazine ve Maliye Bakanı yürütür.

Şahin Bey, yarı öfkeli, yarı neşeli "Yahu ben bu konulardan bıktı̆̆ım için, buralara kaçtım. Gezen tavuk yetiştireceğim. Yarın akşam bari bütün çay bahçesini toplayıp, herkese anlatalım. Kamuyu aydınlatalım... Ama bir kuru çay olmaz karşılı̆̆g.." dedi, bir yandan da tebessüm ediyordu.

\section{Sorular}

1. Sizce Türk Hava Yollarının 2018 yılı sonucu nedir? Kamuya hangisi açıklanmalıdır?

2. UFRS tabloların altında yer alan “Kapsamlı” bölüm neden TL ve ABD doları olarak farklıdır?

3. Bir şirket fonksiyonel parasını nasıl seçmelidir? Belirleyeceği kriterler karar vermekte yeterli değilse ne yapmalıdır. Örneğin, şirket nakit akışlarında iki farklı paranın ağırlığı eşit ise.

4. Fonksiyonel parası bulunduğu ülkenin para biriminden farklı olan başkaca hangi şirketleri söyleyebilirsiniz.

Finansal Destek: Yazarlar bu çalışma için finansal destek almamışlardır. 